\title{
The Secret Lives of Human Herpes Virus 6 (HHV-6)
}

\section{Benjamin M Blumberg*}

Departments of Neurology, Microbiology \& Immunology, University of Rochester Medical School, Rochester, NY, US

\section{Introduction}

Would you believe me if I told you that roseola of infants (Exanthem subitum: ES), childhood viral meningoencephalitis (ME), autism spectrum disorders (ASD), multiple sclerosis (MS) and progressive multifocal leukoencephalopathy (PML) are all the same disorder? Probably not, but it is true, more or less and nonetheless. All these disorders are due to the covert action of a single infectious agent, human herpesvirus-6 (HHV-6). Naturally, there are wheels within wheels, but for the most part, the differences between the disorders are due to differences in the age at which the individual encounters exogenous stimulatory agents that "rile up" HHV-6, to the characteristics of the exogenous agents themselves, and to the nature of their interaction with HHV-6. A few have sensed this sort of continuum [1], and many have struggled to prove that HHV-6 is causally involved in MS by studies on blood and CSF [2]. I and my co-workers and at least four other groups generated neuropathological data over 10 years ago that, in the ensemble, was almost sufficient to prove it [3-13]. I admit that this point of view is still considered controversial by many, but with regard to MS, renowned NIH Infectious Disease Expert Steve Jacobson has commented that "Ultimately, the only way to demonstrate the involvement, or lack thereof, of HHV-6 or other herpesviruses in this disease is through a controlled trial of an efficacious antiviral drug." [14], which unfortunately has not happened yet. Equally unfortunately, citations of this body of work have virtually disappeared from the literature. This Commentary and Brief Review is an effort to set the record straight.

The results are presented as a timeline, roughly in the order in which we encounter these HHV-6-mediated diseases. In an effort to allow the story line to flow uninterrupted, and to make this review more of a commentary, I have minimized the referencing in the text, and provided annotated references at the end, grouped according to the subject material of the text.

\section{The HHV-6 Timeline}

\section{Ages 6 months - 2 years: Roseola}

The first encounter we have with HHV-6 is as a newborn infant. Mommy comes by to kiss us in our cradle and - boom! - we have just acquired HHV-6, which is carried in Mommy's saliva. The ensuing disease thus represents the first emergence of HHV-6 in an immunologically naive host. Usually we don't know we have become infected right away, but within a few weeks or months we may spike a fever of up to $102^{\circ} \mathrm{F}$ that lasts for 2-3 days and develop a more or less obvious viral rash known as Exanthem subitum (ES); this is Roseola [15-17]. Usually, within a couple of days, the fever subsides and the rash goes away and everybody is happy. Even HHV-6 is happy, because it has just infected a sizeable proportion of the oligodendrocytes in our rapidly developing brains, and it is hunkering down for a long stay - the rest of our lives, in fact.

\section{Ages 1 year - 31/2 years: Autism and ASD}

Our second encounter with HHV-6 is likely to be in conjunction with the incredible plethora of vaccinations today's pediatricians insist on giving to infants and toddlers between 1 and $3 \frac{1}{2}$ years of age [17-19].
This is precisely the window of time during which neural connections involved in socialization are forming, in part by so-called "mirror" neurons [20-22] that mediate perception/action and that enable us to evaluate facial expressions; in part by other neurons in Broca's and Wernicke's areas that enable us to speak and respond to speech. The developing brain is a very dynamic place, with synapses connecting and disconnecting rapidly and continuously, on a time scale of milliseconds to seconds. The synaptic connections only become stabilized by becoming myelinated, and myelination proceeds on a timescale of hours to days. The cells that produce the 6 proteins required for myelinating and stabilizing the newly-formed CNS neural connections are the oligodendrocytes, of which many are now infected with HHV6. A TON (relatively and molecularly speaking) of myelin proteins are required to form the lamellae, self-assembling leaf-on-a-stalk-like structures which reach out far from the oligodendrocyte surface and wrap themselves around the newly connected axons and neurites that form synaptic connections with other neurons, slowly becoming the myelin sheath that insulates the connected neurites and axons so they can efficiently conduct electrical signals from one neuron to another.

If one of these 12 vaccines, or an adventitious exogenous agent, contains elements that activate or "rile up" HHV-6, this places a stress on the infected oligodendrocyte, which causes it to withdraw its most differentiated structures and functions [23], namely the myelin proteins and the lamellae, and the now-unshielded, demyelinated and unstable synaptic connections disengage. But the neurites and axons are still out there, searching for new attachments, and soon form new synapses, which then undergo myelination and stabilization by fully functional oligodendrocytes. The result of this is a rewiring process that from the viewpoint of the child means that things he/she was able to do yesterday are impossible to do correctly today. Maybe trying to do something results in total inability to do it; maybe trying results in something unexpected happening. Either way, the child is confused, and angry really pissed off - but lacking words other than mama or dada at the tender age of 1 or a vocabulary sufficient to describe complex feelings up to the age of 3 or 4 , he/she may give up and simply rock back and forth, davening before this incomprehensible misfortune brought to him/her by parents or paediatrician. This, folks, is Autism [24-27]. The exact nature of the exogenous agent or vaccine encountered that "riles up" HHV-6, and the exact age at which the normal developmental process is interrupted, and the exact way in which the rewiring takes place, determines where on the spectrum of ASD the child will fit.

\section{Broad age range, 1 - 8 years more or less: Viral meningitis}

Our third encounter with HHV-6 may be in childhood meningitis

${ }^{*}$ Corresponding author: Benjamin M Blumberg, Departments of Neurology, Microbiology \& Immunology, University of Rochester Medical School, Rochester NY, US, Tel: 201282-4044; E-mail: bbrl@aol.com

Received June 09, 2017; Accepted June 24, 2017; Published June 27, 2017

Citation: Blumberg BM (2017) The Secret Lives of Human Herpes Virus 6 (HHV-6) J Neurol Disord 5: 352. doi:10.4172/2329-6895.1000352

Copyright: ( 2017 Blumberg BM. This is an open-access article distributed under the terms of the Creative Commons Attribution License, which permits unrestricted use, distribution, and reproduction in any medium, provided the original author and source are credited. 
[28-30]. There are many forms of meningitis, most of them bacterial. But in the few cases (less than 1 in 100,000) where the disease is unresponsive to antibiotics and hence the cause is not bacterial, and no other infectious agents can be identified in CSF or brain biopsy material by ordinary light microscopy, one needs to consider that the cause may be HHV-6, "riled up" by some agent that may forever remain unknown (an "exclusionary" diagnosis). HHV-6 meningitis often proves fatal, as there is as yet no drug specific for HHV-6.

\section{Ages 6 - 12+ years: Childhood MS}

Our fourth encounter with "riled up" HHV-6 may occur as early as age 6 , and it shows up mostly as relapsing-remitting MS. Childhood MS is becoming recognized as its own entity, as it may cause as many as $5.4 \%$ of all MS cases under 18 years of age [31,32]. It is not clear why this disorder strikes at these young ages. Perhaps it is because the process of brain development is more complete; myelination is now well established and "compacted" throughout the brain. This gives HHV-6, should it get "riled up" by any agent or event, an opportunity to create "plaques", the hallmark of MS [33], through withdrawal of lamellae by groups of neighboring, infected oligodendrocytes, leaving whitishlooking patches of demyelinated brain tissue here and there when the brain is examined by MRI or at autopsy. Plaques appear to be lacking in brains of autistic younger children. This is partly due to the fact that there are very few neuropathological samples of autistic children for study - children do not die because of autism - and partly due to the fact that myelin takes time - months to years - to "compact" itself, so that demyelinated areas of original neuronal tracts in brains of autistic infants are soon replaced by areas of myelinated replacement tracts as part of the rewiring, leaving few traces behind.

\section{Ages 20+: The heart of the issue - Adult MS}

Our fifth encounter with HHV-6 is perhaps the best-known one: adult MS. For years it was thought that MS occurs mainly in adults between 20 and 50 years of age. This is still true, but "pediatric onset MS is now formally included in the 2010 McDonald criteria for MS" as a separate category [34]. The prevalence of MS in the USA is now approaching $400,000(388,571$ according to the NIAD), or $1 / 700$ individuals (note that this is around 1/10th the incidence of autism at 1/68), and there are around 10,000 new cases of MS per year. This makes MS the most widespread serious neurological disease at the moment, but if treatments cannot be found, ASD will soon catch up. As we, as a population, live to older ages, new and distinctive forms of MS may yet be identified. But the biggest difference between childhood MS and adult MS is that, in children, the disease is due to new infection by specific adventitious environmental agents that "rile up" HHV-6, while in adults, with age and prolonged breakdown of myelin sheaths and lamellae during the disease course, the immune system becomes more and more sensitized to these breakdown products, and the disease becomes more and more an autoimmune process. In children and mid-range adults, MS tends to be relapsing-remitting [35], suggesting that repair processes are occurring [36,37], while in MS patients over 50 the progress of the disease typically becomes more progressive [35], suggesting that the immune system is losing control. The connection between the immune system and MS is reflected in the fact that immune-related drugs such as the interferons and Copaxone ${ }^{\circ}$ were the first reasonably successful MS treatments. However, the even greater success of the two new drugs, Tysabri ${ }^{\circledR}$ and Gilenya ${ }^{\oplus}$, which act to prevent the passage of infectious agents into the CNS, shows that the connection between MS and exogenous or endogenous infectious agents is the stronger connection.

\section{Adult: The bleeding heart of the issue - PML}

The last encounter with HHV-6 that we may have is through the demyelinating disease PML [38,39], and it may be our final encounter of any type as PML is likely to be rapidly fatal. Before the AIDS epidemic, PML used to be rare, occurring in some cancer patients or transplant patients where immune competence was compromised by disease or immune-suppressive drug treatment. During the AIDS epidemic, the incidence of PML rose greatly, due to the immunosuppressive effects of HIV-1 infection, to the point where PML became one of the defining AIDS-associated diseases. After the introduction of successful combined antiretroviral treatment (cART) for HIV-1/AIDS, the incidence of PML plummeted. But more recently, with the introduction of Tysabri ${ }^{\circledR}$ and Gilenya ${ }^{\circledR}$ treatments for MS, the incidence of PML is rising again, so it is important now to get the proper ducks lined up in order to successfully treat PML.

All the medical texts and all the recent review articles and all the online sites like Web MD reflexively state that the cause of PML is the JC virus. Indeed, PML is now so closely associated with the JC virus in the public and medical mind that it seems to have been forgotten that HHV- 6 is always present in the brains of all of us, and that HHV-6 is the central cause of demyelination in MS [3-6,9-13]. In my opinion, HHV6 is also and similarly the cause of demyelination in PML, with JC virus acting as the stimulatory co-agent that "riles up" HHV-6.

\section{The staining problem in glial cells in MS and PML - Gliogen- esis and its reversal}

From the days of Ramon-y-Cajal in the 1800s, neuropathologists have been developing stains for brain structures. Some of the oldest chemical stains include hematoxylin and eosin (H\&E) for cytoplasm and nucleus, and luxol fast blue for myelin basic protein (MBP). Then came more specific, antibody-mediated stains such as glial fibrillary protein (GFAP) for astrocytes and myelin oligodendrocyte protein (MOG) for oligodendrocytes. The hallmark of MS is the classic plaque [33,35-37], one of numerous, often extensive whitish regions in autopsy MS brain sections that stain strongly for GFAP, a marker for astrocytes, and poorly for myelin proteins, suggesting that this is a demyelinated area full of dead astrocytes, the so-called "glial scar". MS plaques also often contain evidence of inflammatory processes, such as of perivascular arrays of lymphocytes, and macrophages/microglia that stain for phagocytized myelin proteins. MS plaque areas have been strongly associated with the presence of HHV-6 [3-6,9-13]. Plaques in PML brains tend to be smaller and more compact but more numerous than in MS, and contain in addition the unique and characteristic "bizarre astrocytes" that stain strongly for GFAP are the neuropathological hallmark of plaque lesions in PML. PML plaques also contain JC virus AND HHV-6, often colocalized in the same cells [4,5]. I got the overwhelming impression that PML plaques were like MS plaques on steroids.

Immunohistological staining of oligodendrocytes in the brain and in culture is tricky, and has led to deceptive results in MS and PML. The neuropathologist faces two linked problems in evaluating the significance of plaques in MS and PML brains. First, it is not sufficiently well understood that both astrocytes and oligodendrocytes descend from the same glial precursor cells, and differentiate early on in order to perform their separate duties - oligodendrocytes to single-mindedly manufacture the TONS of myelin proteins and make the lamellae that are essential for signal propagation by neurons, and astrocytes to provide a large number of functions including sealing the blood-brain-barrier and acting as nurse and feeder cells for neurons and oligodendrocytes. A sizeable pool of glial precursor cells remains in MS lesional areas, as well as in healthy areas [40-43] Healthy glial precursor cells develop as oligodendrocytes by gradually losing their GFAP stainability, and become stainable first with $\mathrm{A} 2 \mathrm{~B} 5$ or $\mathrm{O} 4$ antibodies, then as they 
mature with CNPase or GalC [44-48]. Astrocytes in the brain and in tissue culture are easy to identify by immunohistochemistry for GFAP, a readily available and very powerful and specific antibody-mediated stain. Astrocyte cytoplasm even stains strongly simply with H\&E, and this simple staining pattern continues throughout their development.

Second, in contrast, GFAP staining in the somewhat smaller but numerous lesions in PML brains reveals the characteristic cells termed "bizarre astrocytes": hugely swollen vacuolated cells with strangelooking scalloped borders. What is too often missed is that these GFAP stained "bizarre astrocytes" are not really astrocytes at all: they are wounded HHV-6 infected oligodendrocytes trying hard to survive but losing in the end. As mentioned earlier, a shibboleth of virology is a concept introduced by Michael Oldstone, that when cells are stressed they withdraw their most highly differentiated features [24]. When oligodendrocytes are stressed, they curtail their manufacture of myelin proteins, and begin to withdraw the extensive processes that funnel the myelin proteins to the lamellae. As part of this process, the oligodendrocytes revert to their more primitive astroglial roots: they stop expressing GalC and CNPase or A2B5 and O4 antigens, and again express GFAP. Thus, in PML lesions, the spikes of the scallops on the surface of the "bizarre astrocytes" represent the points where the oligodendroglial processes are being pinched off and detached, and the vacuoles are the factories in which the cell attempts to digest the TONS of myelin proteins that are being pulled back into the cell body. Similarly, the "astrocytic plaque" in MS is probably made up of dead reverted oligodendrocytes as well as astrocytes. Thus, in my opinion, the main difference between MS plaques and PML lesions is the presence in the latter of active JC virus in dually-infected oligodendrocytes, which "riles up" HHV-6 and greatly accelerates the demyelinative damage due to HHV-6.

In our in-situ studies on MS and PML, we were greatly aided by the in vitro studies of Margot Mayer-Proschel and Joerg Dietrich, who established an oligodendrocytic line of glial precursor cells $[47,49]$ and investigated the behaviour of these cells when they were infected with HHV-6. The results, using novel fluorescent-labelled HHV-6A or HHV-6B reagents (made by me) showed strong G1/S phase inhibition in infected precursor cells, but the cells did not die. This cell cycle arrest was accompanied by a profound decrease in expression of the glial progenitor cell marker A2B5 and a corresponding increase in the oligodendrocyte differentiation marker GalC [50,51]. These findings thus represent an in vitro confirmation of the results seen in MS and PML brain tissue sections.

Naturally, there is always an opposite point of view. Steve Goldman and his group first established a line of mice whose brains were chimeric for human glial cells [50], and then showed that JC virus infected astrocytes rather than oligodendrocytes in a PML model using these chimeric mice [51]. This human/mouse model proved useful in tracing some of the parameters of the oligodendrocyte - astrocyte lineage fate switch [52]. When we probed acute MS lesions for HHV-6, the viral DNA was easily identified in plaque regions; however, HHV-6 antigens were very weakly expressed, and appeared in cells with astrocytic rather than oligodendrocytic morphology. We were puzzled by this finding and speculated that the HHV-6 antigen in astrocytes reflected their part-time role as phagocytic cells. Now, I would speculate that HHV-6 antigens are simply not well expressed in brain oligodendrocytes. HHV6 is exceedingly "sticky" in culture, and its antigens are membranebound [53]. Also, in our less high-tech mouse model, using tiny "balls" of human brain tissue transplanted into ordinary mouse brains, the mouse brain itself was resistant to infection by HHV-6, while infection did occur, in oligodendrocytes, in the transplanted human brain tissue (unpublished data). More work remains to be done, to decide which model best represents the actual human diseases MS and PML.

\section{How can HHV-6 get away with causing 6 diseases without being noticed?}

In the brain, HHV-6 is usually latent, indolent and benign. Even when HHV-6 actively infects brain oligodendrocytes, as well as cultured astrocytic or oligodendrocytic cells, it does not kill the infected cells, but rather causes gross swelling and vacuolization of the cells, especially of oligodendrocytes. These features are easy to see by light microscopy in cultured oligodendrocytic cells, even without staining.

HHV-6 is almost universally acquired by 2 years of age. It is thus a commensal virus, and furthermore it has recently been shown to be capable of inserting itself into human chromosomal DNA [19]. Therefore HHV-6 should be thought of as at least potentially endogenous in the human germ line; it is inescapable. Endogeous viruses never stand out in epidemiological studies because they are always present in everybody, so HHV-6 is always missed by epidemiologists. By way of contrast, JC virus is not endogenous; it has a prevalence of around $50 \%$ by age 12 and $80 \%$ by late adulthood, and stands out clearly in epidemiological studies. HHV-6 is highly tropic for oligodendrocytes, but was first identified in lymphocytes, in studies by Robert Gallo's group that also identified HIV-1, so it is often considered a virus of lymphocytes by physicians who do not specialize in diseases of the CNS, and in roseola it is mainly just that. Most physicians understand that HHV-6 causes roseola, but this disease is usually so mild that few know about or worry about its lifelong persistence in the CNS. HHV-6 has been termed a "stealth virus" by WJ Martin and his group [54-56], so it is no surprise that a stealth virus would have a secret life.

\section{Internet fun and games with HHV-6, its co-factors and its disorders}

One of the pleasures of modern science is the ability to access almost all information via the internet. This includes access to Abstracts and sometimes to full articles at NCBI/PubMed and Google Scholar, and the number of times that others cite your papers is detected and archived on ResearchGate.net. The number of "hits" reported when searching PubMed for a subject or an author is a reasonably good measure of the public interest in and knowledge of the targeted item. In order to assess the extent of knowledge about HHV-6, its known co-factors and its disorders as listed above, I performed two-way and three-way "AND" searches on PubMed. The results as of August 30, 2016 are tabulated here, from low to high interest (Table 1).

The results show that there is no awareness of a connection between roseola and autism, and only a dim awareness of connections between

\begin{tabular}{|c|c|}
\hline Items searched & \# of hits \\
\hline Roseola and Autism & 0 \\
\hline Roseola, Autism and MS & 0 \\
\hline Roseola and MS & 4 \\
\hline HHV-6 and Autism & 5 \\
\hline HHV-6 and JCV and PMI & 8 \\
\hline HHV-6 and JCV and MS & 9 \\
\hline HHV-6 and PML & 16 \\
\hline JCV and MS & $158 / 183^{*}$ \\
\hline HHV-6 and MS & $154 / 247^{*}$ \\
\hline HHV-6 and Roseola & 345 \\
\hline JCV and PML & 620 \\
\hline *Higher number when multiple sclerosis is spelled out \\
\hline Table 1: The results as of August 30, 2016. \\
\hline
\end{tabular}


roseola and MS, and between HHV-6 and autism. Bringing JC virus into the picture shows increased awareness of a connection between HHV-6 and MS, even though JCV plays no active role in MS. There is substantial awareness of the connection between hhv-6 and MS; why the connection between JCV and MS is equally high probably has to do with the interest in MS. Public awareness of the connection between hhv- 6 and roseola is fairly high, but the surprise winner in this study is the strong connection between JCV and PML; this must be a sexy topic nowadays. There are many problems with this sort of study; for example, PML also refers to promyelocytic leukemia, so the numbers of hits are far from exact. Nevertheless, this Table shows clearly that HHV$6+$ Roseola and JCV+PML are the pairs that stand out; associations with MS are sketchier even though MS is the best-known disease, and there is absolutely zero awareness of any connection between roseola and autism ${ }^{1}$. Thus, HHV-6 enjoys a remarkably secret life while causing a variety of important human diseases.

\section{Discussion}

It is my hope that this commentary/review has made the etiology of HHV-6-associated disorders clearer; that by viewing the various disorders as a continuum, rather than as separate diseases, the stealthy role of HHV-6 in demyelinating diseases has been illuminated. Once demyelinating diseases are viewed in this way, individual physicians, researchers and the Pharmaceutical Industry can begin to rationally formulate cocktails of drugs to fight these disorders, as was successfully done by cART for HIV-1/AIDS. With HHV-6 as a more clearly defined central target, it is possible to envision a drug cocktail for fighting childhood or adult MS that might consist of four ingredients:

1) An anti-herpetic drug, such as valganciclovir, to suppress replication of activated HHV-6.

2) Tysabri ${ }^{\oplus}$ or Gilenya ${ }^{\oplus}$, to prevent entrance into the CNS of agents that can "rile up" HHV-62.

3) Anti-inflammatory and anti-oxidative compounds, to prevent HHV-6 from getting "riled up" simply by common chronic sub-clinical

${ }^{1}$ In the case of Autism, there has been actual misreporting of data by the CDC several blogs reporting a CDC whistleblowers' statement to the effect that the MMR actually is associated with the onset of ASD are accessible over the Internet (e.g. Obama Grants Immunity to CDC Whistleblower on Measles Vaccine Link to Autism. Medicine Watch; Admin. Feb 4, 2015. And recently, the whistleblower's story was printed in the Townsend Letter 399: 26, 2016. One reason the Government has adopted such a CYA stance is the existence of the Vaccine Injury Compensation Program (VICAP), which seeks to reimburse families of children who sustain medical and financial injury due to vaccines, and thus protect our Nation's vaccine manufacturers [25]. This works well in cases like the Sabin vaccine against polio, which has a finite reversion rate and infects something like six in a million children. However, faced with the Autism Epidemic where the incidence rate is 1 in 68, and there are on the order of 257,000 children at risk for acquiring autism each year, the Government is reluctant to allow blame to be put on widely used vaccines such as the MMR. It is my hope that this report will ease the fears of the Feds somewhat. In my view, ASDs are primarily caused by the virus HHV-6, but it is not a vaccine virus; rather it is a ubiquitous, commensal, sometimes endogenous virus that cannot be avoided, and so Government liability under VICAP should perhaps be reassessed.

${ }^{2}$ Another way to use the Internet is to consult Wikipedia, the Encyclopaedia Brittanica of our age. As of 09/06/2016, when I called up Wikipedia: Autism, there was a decent section on vaccines in general, but there was not a single mention of HHV-6 among 224 reference titles. When I googled up Wikipedia: HHV6 , among its 89 references, there was only a single reference to one of the key neuropathological studies on MS cited above (Challoner et al. [9], while several papers mentioned lack of or disappointment in drug studies. Among the references provided in the present paper, there were a total of only 255 authors, including the unnamed whistleblower. Even if we triple this number, to include authors writing in languages other than english or those not cited simply because of redundancy, we wind up with less than 1000 investigators worldwide who have contributed to the findings here. With the passage of time, interest shifs and memory fades. If only there were an efficacious anti-HHV-6 drug! inflammatory conditions that many of us put up with daily. Common examples of such drugs would be Airborne ${ }^{\oplus}$ and glutathione.

4) A drug such as miconazole or clobetasol, which were serendipitously found to promote remyelination in a study on the MS model disease EAE in mice [57-60].

It is often said of MS, the King of neurological diseases, that if you shoot at the King you must kill him. He is probably not yet dead, but I hope you can see a few vacuoles forming. Aside from the staining problems mentioned above, there are many other factors at work that have kept the pervasive effects of HHV-6 from being better understood. One important factor is that manufacturers of drugs to treat most diseases, including MS and PML, always start by testing their drugs as monotherapy. This is reasonable as long as the disease etiology is not understood, or is controversial. However, now that the multiple roles of the stealthy HHV-6 have been illuminated, it is time to consider targeted clinical trials with drug cocktails, as was ultimately successful for treating HIV-1. Unfortunately, there is no specific drug to block HHV-6 replication, and there may never be one because of the similarity of the HHV-6 DNA polymerase to its human counterpart. Other drugs that prevent or diminish trafficking of lymphocytes through the CNS may yet be found, but Tysabri ${ }^{\circledR}$ and Gilenya ${ }^{\star}$ are already very powerful. Additional drugs that promote remyelination are likely to be found by the same techniques that identified miconazole and clobetasol [60]. Perhaps the most interesting field for experimentation is the great variety of available anti-inflammatories and anti-oxidants that can be tested. Finally, in MS-related PML, which now can now be seen etiologically as simply an extension of MS, the cocktail should include multiple drugs targeted at JC virus, as well as at HHV-6 [61].

\section{Conclusion}

Currently, HHV-6 is not accepted by the medical community as the etiological agent of autism or MS or PML, and it is worth considering why this is so. The medical community rightly holds to a very high standard of proof before starting clinical trials in humans, and there are three main determinants that can provide sufficient motivations. I believe that the HIV-1/AIDS model that inspired the design of the fourpart drug cocktail is a useful basis for comparison. First, the perceived character of the disease must be very pressing. At the beginning of the AIDS era, the disease was rapidly fatal, and the number of HIV-1 infected individuals was rapidly expanding with no end in sight; the numbers of HIV-1 infected individuals eventually reached into the millions. Second, the science must be incontrovertible. In the case of HIV-1/AIDS, the role of HIV-1 was at first questioned even after its discovery, but there was a perfect animal model: SIV (and later HIV2) in monkeys. Third, there must be enough political pressure brought to force clinical trials. In HIV-1/AIDS, the gay community suffered so conspicuously and so severely early on that they organized political pressure groups to reformulate and accelerate diagnosis and treatment protocols, and both shortened the time to treatment and reduced the number of controls required for conclusive testing.

In striking contrast, in regard to MS, the number of patients is high but not rising at about 500,000, and MS is not perceived as rapidly fatal. In fact, the disease has been around so long that a degree of acceptance has emerged. Autism, although it has recently risen in incidence to an alarming level, is not fatal; it is more of a problem in therapy. In contrast to SIV or HIV-2 in monkeys, HHV-6 does not infect nonhuman animals, and a recombinant mouse model yielded weird results, perhaps due to the staining problem. The continued lack of a specific drug for HHV-6 also helps maintain disbelief. Perhaps only PML, the incidence of which is rising along with treatments for MS that reduce 
immune surveillance of the brain, and which is much more rapidly fatal than MS, will serve as a catalyst for increased political pressure. If the reasoning presented above remains insufficient to convince clinicians to perform these trials, then the proof of the proposed multiple roles of HHV-6 may have to await transcriptome sequencing studies, a drawnout, back-to-front approach $[62,63]$.

This paper is also written for the patient, to promote more intensive and effective treatment for HHV-6-related demyelinating diseases. In this regard, a reviewer of this manuscript noted the emergence of care manager groups in Italy. It is well known that Italian health care and European practices in general, pay much time and personal attention to patients' perceived well-being. The four-part cocktail described here suggests that care managers could be very useful in testing and evaluating most of the individual components, and spare the primary physicians much time and effort. Among the four categories of drugs, only two are prescription items - the anti-herpes drugs (valganciclovir or possibly Zovirax) and the immune blockers Tysabri ${ }^{\circledR}$ and Gilenya ${ }^{\circledR}$ and only the latter demand the physician's close and direct oversight, because of the risk of PML. Care managers could very well be made responsible for choosing among the multiple anti-inflammatory and antioxidant drugs on the market, and should also be responsible for carefully observing and recording the effects of their chosen drugs on the patients in their care. Miconazole and clobetasol represent a mid-range of responsibility due to the fact that these drugs are very insoluble in water, and would require a manufacturing pharmacist to prepare them in patient-usable form. It is my hope that there is enough material here to inspire the medical community and the care managers to cooperate in inaugurating well-targeted clinical trials; if successful, these trials would then constitute proof of the HHV-6 link.

\section{References}

1. Goldberg MJ, Goldberg E (2001) The myth of autism: How a misunderstood epidemic is destroying our children. Skyhorse Publishing, New York.

2. Regush N (2000) The virus within: A coming epidemic. Dutton Books, New York.

3. Knox KK, Brewer JH, Henry JM, Harrington DJ, Carrington DR (2000) Human herpesvirus 6 and multiple sclerosis: systemic active infections in patients with early disease. Clin Infect Dis 31: 894-903.

4. Mock DJ, Powers JM, Goodman AD, Blumenthal S, Ergin N, et al. (1999). Association of human herpesvirus 6 with the demyelinative lesions of progressive multifocal leukoencephalopathy. J Neurovirol 5: 363-73.

5. Blumberg BM, Mock DJ, Powers JM, Ito M, Assouline JG, et al. (2000) The HHV6 Paradox: Ubiquitous Commensal or Insidious Pathogen? A Two-step PCR approach. J Clin Virol 16: 159-178.

6. Goodman AD, Mock DJ, Powers JM, Baker JV, Blumberg BM (2003) Human Herpesvirus 6 Genome and Antigen in Acute Multiple Sclerosis Lesions. J Inf Dis 187: $1365-1376$

7. Gelbard HA, James HJ, Sharer LR, Perry SW, Saito Y, Kazee AM, et al. (1995) Apoptotic neurons in brains from paediatric patients with HIV-I encephalitis and progressive encephalopathy. Appl Neurobiol 21: 208-217.

8. Krajewski S, James HJ, Ross J, Blumberg BM, Epstein LG, et al. (1997) Expression of pro- and anti-apoptosis gene products in brains from pediatric patients with HIV-1 encephalitis. Neuropathol Appl Neurobiol 23: 242-253.

9. Mock DJ, Chugh P, Kim B, Proschel C, Dietrich J, et al. (2006) Characterization of specific HHV- 6 and cell cycle genes implicated in virus-mediated G1/S cell cycle arrest of glial precursors. Retrovirology 3: 65 .

10. Challoner PB, Smith KT, Parker JD, MacLeod DL, Coulter SN (1995) Plaqueassociated expression of human herpesvirus 6 in multiple sclerosis. Proc Natl Acad Sci 92: 7440-7444.

11. Sanders VJ, Felisan S, Waddell A, Tourtellotte WW (1996) Detection of herpesviridae in postmortem multiple sclerosis brain tissue and controls by polymerase chain reaction. J Neurovirol 2: 249-258.

12. Daibata M, Hatakeyama N, Kamioka M, Nemoto Y, Hiroi M, et al. (2001)
Detection of human herpesvirus 6 and $\mathrm{JC}$ virus in progressive multifocal leukoencephalopathy complicating follicular lymphoma. Am J Hematol 67 200-205.

13. Yao K, Gagnon S, Akhyani N, Williams E, Fotheringham J, et al. (2008) Reactivation of human herpesvirus- 6 in natalizumab treated multiple sclerosis patients. Plos ONE 3: 1-8.

14. Leibovitch EC, Jacobson S (2014) Evidence linking HHV-6 with multiple sclerosis: an update. Curr Opin Virol 9: 127-133.

15. Pruksananonda P, Hall CB, Insel RA, McIntyre K, Pellett PE, et al. (1992) Primary human herpesvirus 6 infection in young children. N E J Med 326: 1445-1450.

16. Hall CB, Long CE, Schnabel KC, Caserta MT, McIntyre KM, et al. (1994) Human herpesvirus- 6 infection in children. A prospective study of complications and reactivation. N Engl J Med 331: 432-438.

17. Spock B (1946) The commonsense book of baby and child care. Am J Nurs 47: 139.

18. Sears W, Sears M, Sears R, Sears J, Sears P (2011) The Portable Pediatrician: Everything you need to know about your child's health. (1st edn) Little, Brown and Company, New York.

19. Pellett PE, Ablashi DV, Ambros PF, Agut H, Caserta MT, et al. (2012) Chromosomally integrated human herpesvirus 6: questions and answers. Rev Med Virol 22: 144-155.

20. Sears RW (2011) The vaccine book: Making the right decision for your child Sears Parenting Library, Little, Brown \& Company, New York.

21. Rizzolatti G, Craighero L (2004) The mirror-neuron system. Annu Rev Neurosc 27: 169-192.

22. Keysers C (2009) Mirror neurons. Curr Biol 19: R971-973.

23. Jarrett C (2013) A calm look at the most hyped concept in neuroscience - Mirror neurons. Wired 12: 13

24. Oldstone MB, Sinha YN, Blount P, Tishon A, Rodriguez M, et al. (1982) Virusinduced alterations in homeostasis: alteration in differentiated functions of infected cells in vivo. Science 218: 1125-1127.

25. Offitt PA (2008) Autism's false prophets: Bad science, risky medicine, and the search for a cure. Columbia University Press, New York.

26. Offitt PA (2011) Deadly choices: How the anti-vaccine movement threatens us all. Basic Books, New York.

27. Habakus LK, Holland M, Rosenberg KM (2013) Vaccine epidemic: How corporate greed, biased science, and coercive government threaten our human rights, our health, and our children. Skyhorse Publishing, New York.

28. Miller NZ (2012) Vaccines: Are they really safe and effective? New Atlantean Press, New York.

29. Ito M, Baker JV, Mock DJ, Goodman AD, Blumberg BM, et al. (2000) HHV6-meningoencephalitis in an HIV patient with progressive multifocal leukoencephalopathy. Acta Neuropathol 100: 337-341.

30. Gewurz BE, Marty FM, Baden LR, Katz JT (2008) Human herpesvirus 6 encephalitis. Curr Infect Dis Rep 10: 292-299.

31. Sadighi Z, Sabin ND, Hayden R, Stewart E, Pillai A (2015) Diagnostic clues to human herpesvirus 6 encephalitis and Wernicke's encephalopathy after pediatric hematopoietic cell transplantation. J Child Neurol 30: 1307-1314.

32. Belman AL, Krupp LB, Olsen CS, Rose JW, Aaen G, et al. (2016) Characteristics of children and adolescents with multiple sclerosis. Pediatrics 138: 1-8.

33. Waubant E, Ponsonby AL, Pugliatti M, Hanwell H, Mowry EM, et al. (2016) Environmental and genetic factors in pediatric inflammatory demyelinating diseases. Neurology 87: S20-27.

34. Frohman EM, Racke MK, Raine CS (2006) Multiple sclerosis--the plaque and its pathogenesis. N Engl J Med 354: 942-955.

35. Tardieu M, Banwell B, Wolinsky J, Pohl D, Krupp LB (2016) Consensus definitions for pediatric MS and other demyelinating disorders in childhood: Neurology 87: S8-11.

36. Lucchinetti C, Bruck W, Parisi J, Scheithauer B, Rodriguez M, et al. (2000) Heterogeneity of multiple sclerosis lesions: implications for the pathogenesis of demyelination. Ann Neurol 47: 707-712. 
37. Prineas J, Barnard RO, Kwon EE, Sharer LR, Cho ES (1993) Multiple sclerosis: Remyelination of nascent lesions. Ann Neurol 33: 137-151.

38. Barnett MH, Prineas JW (2004) Relapsing and remitting multiple sclerosis: pathology of the newly forming lesion. Ann Neurol 55: 458-468.

39. Major EO, Amemiya K, Tornatore CS, Houff SA, Berger JR (1992) Pathogenesis and molecular biology of progressive multifocal leukoencephalopathy, the JC virus-induced demyelinating disease of the human brain. Clin Microbiol Rev 5: 49-73.

40. Demeter LM (2000) JC, BK and other polyomaviruses: Progressive multifocal leukoencephalopathy. In: Mandell, Douglas and Bennet's principles and practice of infectious diseases, (5th edn), Chapter 134, Churchill Livingston Press, London.

41. Britt WJ, Alford CA (1996) Cytomegalovirus. In: Fields BN, Knipe DM, Howley PM (eds) (3rd edn) Fields Virology. Lippincott-Raven, Philadelphia, New York.

42. Koralnik IJ (2006) Progressive multifocal leukoencephalopathy revisited: Has the disease outgrown its name? Ann Neurol 60: 162-173.

43. Chitnis T, Ghezzi A, Bajer-Kornek B, Boyko A, Giovannoni G, et al. (2016) Pediatric multiple sclerosis: escalation and emerging treatments. Neurology 87: S103-109, 2016

44. Wolswijk G (1998) Chronic stage multiple sclerosis lesions contain a relatively quiescent population of oligodendrocyte precursor cells. J Neurosci 18: 601 609.

45. Warrington AE, Barbarese E, Pfeiffer SE (1992) Stage specific, (O4+GalC-) isolated oligodendrocyte progenitors produce $\mathrm{MBP}+$ myelin in vitro. Dev Neurosci 14: 93-97.

46. Duchala CS, Asotra K, Macklin WB (1995) Expression of cell surface markers and myelin proteins in cultured oligodendrocytes from neonatal brain of rat and mouse: A comparative study. Dev Neurosci 17: 76-80.

47. Chang A, Nishiyama A, Peterson J, Prineas J, Trapp BD (2000) NG-2 positive oligodendrocyte progenitor cells in adult human brain and multiple sclerosis lesions. J Neurosci 20: 6404-6412.

48. Dietrich J, Noble M, Mayer-Proschel M (2002) Characterization of A2B5+ glia precursor cells from cryopreserved human fetal brain progenitor cells. Glia 40: 65-77.

49. Dietrich J, Blumberg BM, Roshal M, Baker JV, Hurley SD, et al. (2004) Infection with an endemic human herpesvirus disrupts critical glial precursor cell properties. J Neurosci 24: 4875-4883.

50. Lee JC, Mayer-Proschel M, Rao MS (2000) Gliogenesis in the central nervous system. Glia 30: 105-121.
51. Zhang L, He X, Liu L, Jiang M, Zhao C, et al. (2016) Hdac3 interaction with p300 histone acetyltransferase regulates the oligodendrocyte and astrocyte lineage fate switch. Dev Cell 36: 316-330.

52. Kondo Y, Windrem MS, Zou L, Chandler-Mitello D, Schanz SJ, et al. (2014) Human glial chimeric mice reveal astrocytic dependence of JC virus infection. J Clin Invest 124: 5323-5336.

53. Windrem MS, Schanz SJ, Morrow C, Munir J, Chandler-Mitello D, et al. (2014) A competitive advantage by neonatally engrafted human glial progenitors yields mice whose brains are chimeric for human glia. J Neurosci 34:16153-16161.

54. Padilla JA, Nii S, Grose C (2003) Imaging of the varicella zoster virion in the viral highways: comparison with herpes simplex viruses 1 and 2 , cytomegalovirus, pseudorabies virus, and human herpes viruses 6 and 7 . $J$ Med Virol 70: S103-119.

55. Martin WJ (1995) Stealth virus isolated from an autistic child. J Autism Dev Disord 25: 223-224.

56. Martin WJ (2003) Complex intracellular inclusions in the brain of a child with a stealth virus encephalopathy. Exp Mol Path. 74: 179-209.

57. Descamps V, Mikoko T, Yoko K, Tetsuo S (2014) HHV-6A and HHV-6B in drug-induced hypersensitivity syndrome/drug reaction with eosinophilia and systemic symptoms. (3rd edn), Elsevier Science Publishers, Netherlands.

58. Najm FJ, Madhavan M, Zaremba A, Shick E, Kari RT, et al. (2015) Drug-based modulation of endogenous stem cells promotes functional remyelination in vivo. Nature 522: 216-220.

59. Bech E, Lycke J, Gadeberg P, Hansen HJ, Malmestrom C, et al. (2002) A randomized, double-blind, placebo-controlled MRI study of anti-herpes virus therapy in MS. Neurology 58: 31-36.

60. Blick G, Whiteside M, Griegor P, Hopkins U, Gafton T, et al. (1998) Successful resolution of progressive multifocal leukoencephalopathy after combination therapy with cidofovir and cytosine arabinoside. Clin Infect Dis 26: 191-192.

61. Shao Q, Lin Z, Wu X, Tang J, Lu S, et al. (2016) Transcriptome sequencing of neurologic diseases associated genes in HHV-6A infected human astrocyte. Oncotarget 7: 48070-48080.

62. Kawada JI, Okuno Y, Torii Y, Okada R, Hayano S, et al. (2016) Identification of viruses in cases of pediatric acute encephalitis and encephalopathy using nextgeneration sequencing. Sci Rep 6: 33452.

63. Ciccone MM, Aquilino A, Cortese F, Scicchitano P, Sassara M, (et al). Feasibility and effectiveness of a disease and care management model in the primary healthe care system for patients with heart failure and diabetes (Project Leonardo). Vasc Health Risk Manag 6: 297-305. 